\title{
O PROJETO POLÍTICO-EDUCACIONAL AZEVEDIANO NO BRASIL NOS ANOS 1920-1930
}

\author{
Magna Maria da Silva ${ }^{1}$ \\ Amélia Kimiko Noma ${ }^{2}$
}

\begin{abstract}
RESUMO
O objetivo deste artigo é analisar as principais ideias de Fernando de Azevedo e sua atuação como formulador de projeto político-educacional no Brasil no período de 19201930. Ao adotar o materialismo histórico como método de investigação, analisa-se o objeto de estudo em articulação com o processo de transformação da sociedade brasileira no contexto delimitado. A proposição do presente trabalho justifica-se pela utilização de uma vertente analítica pouco desenvolvida nos estudos sobre a temática. Trata-se da focalização de Fernando de Azevedo como um agente do governo em ação, como planejador e administrador de políticas educacionais, portanto, sob o prisma da pesquisa em política educacional. O pensamento educacional de Azevedo e a sua ação se articularam a um processo de transformação da sociedade capitalista brasileira ao se engajar na luta para a construção de um sistema nacional de ensino público sob a tutela do Estado, em consonância com uma civilização urbano-industrial moderna.

Palavras-chave: Educação pública; Projeto político-educacional; Fernando de Azevedo; Brasil 1920-1930.
\end{abstract}

\section{THE POLITICAL-EDUCATIONAL PROJECT BY FERNANDO DE AZEVEDO IN BRAZIL DURING THE PERIOD 1920-1930}

\section{ABSTRACT}

The article aims to analyze the main ideas of Fernando de Azevedo and his acting as the developer of the political-educational project in Brazil from 1920 to 1930. The historical materialism is adopted as the method of investigation, and the object of study is analyzed in articulation with the transformation process of Brazilian society in the context under study. The proposition of this work is justified by the use of an analytic branch with scarce studies on this theme. It is about focusing on Fernando de Azevedo as a government agent in action, as a planner and manager of educational policies, thus under the perspective of research on educational policies. Azevedo's educational thinking and his action articulate with the process of transformation of the Brazilian capitalist society, particularly when he engages in the fight for the construction of a national system of public education in line with a modern urban-industrial civilization.

Keywords: Public education; Political-educational project; Fernando de Azevedo; Brazil 1920-1930.

\section{Introdução}

O objetivo deste trabalho é apresentar as linhas diretoras do pensamento educacional e do projeto político-educacional de Fernando de Azevedo (1894-1974), nos anos 1920 e 1930, e inseri-lo no ambiente intelectual que caracterizou o momento histórico brasileiro estudado.

A leitura da obra de Fernando de Azevedo, bem como a de seus analistas, leva à construção da imagem de um homem comprometido com as grandes questões sociais de 
seu tempo, de uma erudição a toda prova - passeia pela crítica literária, pelo jornalismo, pela sociologia, literatura, economia, filosofia, pedagogia, educação e administração pública - e de um ímpeto político admirável. Sobressai a figura de um intelectual, no sentido restrito da palavra: um homem que trabalha com o intelecto, com as ideias; mas, e isto é a nossos olhos o que mais o caracteriza, ele é, também um homem de ação.

Para Cunha (2001), o que caracteriza o campo educacional são questões práticas, as quais estão profundamente entrelaçadas ao meio político e social. Os intelectuais que se dedicaram ao tema da educação foram impelidos a construir seus pensamentos e ideias com o objetivo de resolver problemas que se apresentaram concretamente num contexto determinado. Mesmo que tais intelectuais tenham recorrido a conjuntos teóricos e explicativos formulados em outros ambientes, como ocorreu com os que se agruparam em torno da Escola Nova e, de suas matrizes, retiraram pressupostos que puderam embasar suas formulações, isto ocorreu colado ao contexto político e social local. Seus pensamentos e ideias foram construídos tendo por mote encontrar soluções que coubessem na realidade nacional.

Podemos afirmar, embora correndo risco de superdimensionar a posição assumida por Fernando de Azevedo dentro do pensamento educacional brasileiro, que ele foi um intelectual-síntese desta maneira de pensar a educação nacional. Formulou e sistematizou seu pensamento com vistas a solucionar a problemática da educação no país, apesar de não se restringir apenas a ela. Na tentativa de encontrar saída para questões postas pela nova configuração social, cuja desintegração da economia agrário-exportadora trazia, ao elaborar seu projeto político-educacional, recorreu a doutrinas filosóficas e científicas para justificá-lo e lhe dar legitimidade. No caso, o arcabouço teórico-filosófico-prático escolanovista: Dewey, Kerschensteiner, Pestalozzi, Decroly, além outros sistemas explicativos, como os de Dürkheim, Pareto, Marx, entre outros.

Fernando de Azevedo é incluído entre o grupo composto por "[...] intelectuais que apresentavam identidades plurais, constituídas a partir da produção muitas vezes articulada entre pensamento e ação" (PINTO ET AL., 2000, p. 33). O pensamento de Fernando de Azevedo ganha clareza quando relacionado ao contexto sócio-histórico da época, à sua pretensão político-administrativa e à sua ação enquanto homem de política, de governo.

Ele participou, ativamente tanto das reformas educacionais quanto da produção teórica que cimentaria o ideário renovador. Em 1926, com o Inquérito sobre a Educação Pública do Estado de São Paulo ${ }^{3}$, iniciou seu percurso de "grande renovador" da educação brasileira. A partir daí, ocupou vários cargos públicos administrativos. Foi Diretor Geral da Instrução Pública do Distrito Federal entre 1927-1930, quando projetou, defendeu e realizou, numa campanha de quatro anos, a reforma do ensino que ficou conhecida como Reforma Fernando de Azevedo. Em São Paulo em 1933, quando foi Diretor Geral da Instrução Pública do Estado, criou o Código da Educação; em 1945, foi Secretário da Educação e Saúde do Estado e Secretário da Educação e Cultura da Prefeitura de São Paulo em 1961. As duas últimas foram atuações menos contundentes, ficou no cargo por poucos meses e os pedidos de exoneração foram feitos sob a alegação de falta de apoio dos governos para a execução de seu trabalho.

Este estudo aborda o período 1920-1930, por ser nele que se concentram as suas reformas mais expressivas, a de 1927-1930 e a de 1933. A decisão de estudar este período foi feita em consonância com a trajetória de Fernando de Azevedo. Por abranger os anos finais da República Velha e perpassar pelo Governo Provisório (1930-1934), o momento está pontilhado de contradições e conflitos. A análise pretende assinalar não apenas os aspectos efêmeros, conjunturais, mas apreender o movimento mais profundo de mudança de base estrutural, sem permanecer circunscrita aos aspectos fenomênicos. Propõe-se a 
superar as implicações relativas à periodização política, entendendo que as transformações neste campo articulam-se às mudanças da base econômica do país, uma vez que, a nosso ver, o período estudado guarda uma unidade: o movimento do capitalismo no Brasil. No seio da sociedade agrária, exportadora e mercantil, já se impõe a necessidade material de uma sociedade de tipo urbana, industrial e, portanto, de um capitalismo mais complexo.

É o período de consolidação da sociedade capitalista propriamente dita no Brasil. Para estudar o percurso do autor em foco, consideramos o fato de que sua trajetória se dá num contexto de rápidas transformações no campo político.

\section{O projeto político-educacional azevediano}

Fernando de Azevedo anteviu, nas prerrogativas do movimento internacional da Escola Nova, o modelo ideal de escolarização para a sociedade urbana e industrial que se insinuava no Brasil nos anos 1920-1930. Entendeu que as exigências democráticas que tal sociedade trazia, inclusive a educação do povo, engendravam uma nova forma de sociabilidade e uma nova configuração social que passava pela escola, pelo Estado e pela cultura.

Abre-se um parêntese para explicar, desde já, a concepção de cultura de Fernando de Azevedo. Como indica Dimas (1994, p. 22), o intelectual separa os conceitos civilização e cultura, entendendo esta última como desdobramento da primeira e como resultado da criação de espíritos esclarecidos. Cultura, para ele, equivalia ao saber, ao conhecimento de uma determinada época e sociedade.

É preciso considerar que, no período e no espaço estudado, as lutas no interior do bloco no poder se acirraram e tiveram importante papel na transformação da sociedade. As frações que compunham este bloco tiveram a iminência de estabelecer novos compromissos e efetivar uma rearticulação do poder que, por sua vez, fomentou transformações nas formas de relações e configurações do social. Por exemplo, o advento da chamada "Revolução de 1930", que, guardadas as devidas dimensões, inseriu na sociedade agroexportadora novos elementos, que contribuíram para a dissolução do modelo político-econômico da República Velha.

Não assumimos os acontecimentos de outubro de 1930 como uma revolução no sentido de uma ruptura com toda a estrutura do poder dominante na época e que teria possibilitado a inclusão da imensa maioria da população a uma verdadeira participação política; pelo contrário, houve uma continuidade, embora o exercício da dominação tivesse adquirido novas formas. Por outro lado, é inquestionável a ruptura jurídico-política que o evento introduziu e a rearticulação das frações de classes no poder.

Concernente a esta argumentação na construção deste trabalho, utilizam-se acepções desenvolvidas por Poulantzas (1971), em especial suas formulações em torno da ideia de bloco no poder e fração autônoma de classe. Nesta perspectiva, a classe que detém o poder não é uma classe homogênea, e sim conflituosa, com interesses contraditórios. Para se constituir em fração autônoma de classe, é preciso que determinado grupo social tenha participação econômica, entretanto não exclusiva e nem predominante. O princípio fundante é que sua existência econômica seja observada, ou tenha repercussões políticas e ideológicas específicas, constituindo-se em uma força social autônoma. Isso porque as classes sociais não existem fora da luta de classe. É por meio da luta concreta entre as classes e frações de classes que é possível observá-las, é o processo histórico que dá significado ao conceito.

Pensar em fração de classe dominante e em hegemonia, na perspectiva de Poulantzas, pressupõe a existência de interesses conflitantes dentro da classe dominante. 
Com a investigação de tais interesses e de como esta classe resolve as contradições, podese perceber frações autônomas de classes, bem como frações hegemônicas de classe. Aproximando-se das formulações de Gramsci (2005, p. 24), para o qual "[...] a existência da hegemonia pressupõe [...] certo equilíbrio de compromisso [...] esses compromissos e sacrifícios não concernem o essencial [...]". Poulantzas (1971) explicita a luta dentro da classe que constitui o bloco no poder, no interior da classe dominante, e não apenas como processo de conformação ético-político e econômico na luta entre classe dominante e classe dominada, conforme a visão gramsciana. Como bem acentuou Perissinotto (1994, p.34), é claro, no entanto, que tais concepções se complementam, porque "[...] a classe ou fração que se pretende hegemônica precisa sê-lo nos dois sentidos [...]".

Desde, pelo menos, finais da República Velha, já era possível detectar uma fração da classe dominante ciente de seus interesses industriais particulares, isto é, que conflitava com os interesses de outros grupos que compunham essa classe, cujos interesses estavam voltados especificamente para os negócios agro-exportadores. Não foi apenas com o advento dos anos 1930 ou nos finais dos 1950 que os interesses industriais se colocaram política e ideologicamente de forma específica e muito menos que estes marcos encerrassem, totalmente, o poder das frações que foram hegemônicas na sociedade agroexportadora. A categoria de bloco no poder nos permite compreender tais disputas no interior da classe dominante de maneira ampla.

A estruturação da classe dominante na República Velha foi constituída de frações de classe autônomas: a fração agrária, ligada exclusivamente à produção de café, uma fração subordinada que, no compromisso que foi estabelecido dentro do bloco no poder, não sobrepôs seus interesses de modo hegemônico. A burguesia comercial urbana, que dominou a atividade exclusivamente produtiva e foi politicamente hegemônica. Porém não houve apenas essas duas frações autônomas de classe. A atividade industrial deu origem a uma burguesia industrial consciente da especificidade dos seus interesses. Embora subordinada à fração hegemônica, que, neste momento, é a chamada burguesia comercial urbana (PERISSINOTTO, 1994).

A burguesia comercial urbana deveu sua presença hegemônica à diversificação de seus empreendimentos. Foi um capital diretamente vinculado à produção de café que fez a negociação entre produtor e comprador. Ao mesmo tempo, distanciou-se desse setor meramente produtor à medida que diversificava seus investimentos. Direcionando seus interesses para outros setores da economia, deteve não apenas as casas exportadoras, mas, muitas vezes, o setor bancário e o ferroviário. Pode-se entendê-la como "[...] a camada superior da burguesia cafeeira" (PERISSINOTO, 1994).

Ao examinar a relação entre coronelismo e Estado burguês, Saes (s.d.) toca neste tema, desmistifica a ideia de que os "coronéis", na República Velha, detinham o poder do Estado. Para o autor, a "[...] política de Estado executada pela burguesia cafeeira esteve longe de satisfazer o proprietário ou fazendeiro do interior, cujas queixas contra o governo federal se prolongaram por quase todo o período [...]" (p. 120). Isto porque a política do coronelismo, com seus currais eleitorais, não propiciou a esse grupo (coronéis) o controle do aparelho central de Estado. Na realidade, entende Saes (s.d) que esta organização do poder regional favoreceu a burguesia comercial e urbana e o capital imperialista.

É oportuno destacarmos que as práticas políticas dos coronéis, apesar de favorecerem a perpetuação da burguesia comercial e urbana no comando do Estado, não foram responsáveis pelo poder, ou dito de outra forma, não colocaram tal fração dominante no poder. O raciocínio é inverso, foi justamente com a entrada deste grupo (burguesia comercial cafeeira e urbana) na direção do aparelho central do Estado que a política 
coronelista se desenvolveu, isto é, foram práticas políticas derivadas das forças que assumiram o poder de Estado (SAES, s.d.).

Com base na análise dos estudos de Saes (s.d.) e Perissinoto (1994), pode-se dizer que a sociedade agroexportadora, desde os primeiros anos do período republicano, teve um setor urbano desenvolvido que fez frente, seja econômica ou politicamente, à elite agrária. Estes estudos indicam outros pontos sobre a questão do regionalismo da economia agroexportadora, eram, especialmente, as frações paulistas que detinham a hegemonia política.

Esta afirmação pode nos levar a visualizar as lutas no interior da classe dominante como lutas intrarregionais. Entretanto, na arena política, é preciso ampliar essa discussão, procurando "[...] entender o regionalismo, sobretudo, como expressão de conflitos no interior do bloco no poder" (PERISSINOTTO, 1994, p. 19). Como a atividade mais rentável no período era a produção do café e não a de açúcar ou de algodão - como em outros períodos da história do Brasil -, eram, justamente, as frações ligadas a essa produção que detinham maior expressão econômica. Com a República, parecem ter tomado de vez as rédeas da direção política do país ${ }^{4}$.

Ademais, a produção de café estava concentrada na Região Centro-Sul, sobretudo no estado de São Paulo, o que explica a predominância dos interesses de frações de classe deste estado sobre a dos demais. Esta constatação ainda não dá conta de explicar a luta no interior do bloco no poder. É preciso entender que a fração ligada ao café foi composta de subfrações que lutavam na defesa de seus interesses específicos.

Nos anos 1920, os conflitos tornaram-se mais acirrados, a crise da economia cafeeira e as pressões dos outros estados da federação, especialmente, Rio Grande do Sul, Pernambuco, Bahia, Rio de Janeiro, para maior inserção na condução da política nacional, abalaram a hegemonia política das elites paulistas. Por outro lado, o crescimento da população urbana no Estado de São Paulo inseriu novos problemas, as multidões urbanas. O período teve transformações profundas, seja na relação intraelites, na configuração do bloco no poder ou na relação de dominação. Nesse momento, os projetos societários formulados nos vários meios, não apenas no educacional, foram unívocos ao menos num ponto: a necessidade da adequação do fator humano às novas características sociais, dito de outra forma, a necessidade de formar o trabalhador para a nova organização do trabalho e disciplinar os comportamentos individual e social das multidões.

Fernando de Azevedo interpretou esses sinais e viu na escola uma instituição apropriada para esta função. Em sua perspectiva, a educação, como atividade social, deveria se enquadrar no espírito de sua época, seguir o nível de desenvolvimento da civilização e não apenas instruir, no sentido de ensinar a ler, escrever e contar. Para ele, o que caracterizava o espírito da civilização em sua época era: a indústria, a democracia e a racionalização da vida, tudo possibilitado pelo avanço da ciência.

Sua crença no poder da ciência é um axioma identificável à primeira leitura de qualquer de suas peças. Não se pode compreender seu pensamento sem ter em mente esta característica de seu construto teórico. A introdução do pensamento e da lógica científica nas questões educacionais, seja na administração escolar, nos conteúdos ou nos métodos, garantiria três coisas fundamentais em sua perspectiva: primeiro, possibilitaria colocar os indivíduos em acordo com seu tempo; segundo, prepará-los-ia para o trabalho; e, terceiro, fomentaria os ideais democráticos, a solidariedade e a cooperação entre as classes (AZEVEDO, s.d.a, p. 19).

Imerso num contexto em que a população urbana, apesar de ainda não ser preponderante, já fazia sentir sua forte presença. E as transformações no mundo do trabalho, decorrentes da paulatina industrialização, indicavam que novas relações sociais 
estavam em curso. O trabalho, no projeto político de Fernando de Azevedo, teve proeminência.

O maior contingente populacional do país no período ainda se encontrava no campo, no entanto, nesse momento, observava-se um crescimento substancial dos centros urbanos. Para que se tenha uma ideia, a cidade de São Paulo, em 1920, possuía 500.000 habitantes e essa população iria dobrar em apenas dez anos, em 1931, ultrapassou a casa de um milhão de pessoas (SEVCENKO, 1993, p. 85). A própria expansão da indústria expressou a importância das cidades na geografia e na economia do país. No ano de 1920, havia 13.336 estabelecimentos industriais e 276.000 operários (RIBEIRO, 1986, p. 91), considerando toda a década, o crescimento do setor industrial paulista fechou com 6,6\% a.a. e o do resto do país com taxa de 3,4\% a.a (MOURA, 2001, p. 83). Esse crescimento da indústria representou, socialmente, "[...] a consolidação de dois componentes: a burguesia industrial e o operariado" e este último representou "[...] a existência, a partir daí, do povo enquanto expressão política [...]" (RIBEIRO, 1986, p. 92).

Esse movimento histórico foi detectado pelo intelectual que, ao explicar seu projeto político-educacional, deixa claro: foi formulado "[...] adaptado à nova concepção social baseada no desenvolvimento crescente das ciências e das indústrias e na expansão correlata das classes operárias". É esse processo de mudança na base da sociedade que, segundo ele, exigiu que a educação passasse a contemplar três princípios fundamentais: da comunidade, da escola única e da escola do trabalho (AZEVEDO, s.d.a, p. 42).

Neste ponto, apoiamo-nos em Gramsci (1991, p. 396), que concluiu, ao examinar o fordismo nos Estados Unidos: “[...] os novos métodos de trabalho estão indissoluvelmente ligados a um determinado modo de viver, de pensar e de sentir a vida; não é possível obter êxito num campo sem obter resultados tangíveis no outro". Sintonizado com sua época, Azevedo consensuou com as ideias presentes em seu tempo, entendeu que uma mudança na base econômica do país - o processo de industrialização - implicava em uma mudança na esfera social. A formação do trabalhador e do cidadão era uma exigência da industrialização, que necessitava não só de mão de obra adequada e de consumidores, como de uma fração da burguesia comercial, que via na aceleração da urbanização novos mercados. A outra era uma necessidade política da fração ligada à indústria para conquistar a hegemonia dentro do bloco no poder, ainda que esta última acepção não fosse claramente percebida naquele momento.

É uma constante em sua obra o enfoque da atualidade de sua perspectiva, que denominou de prático-idealista, sugerindo que sua proposta para a sociedade brasileira articulasse, sem atritos ou incongruências, os grandes ideais necessários para o progresso da nação - leia-se a formação da nacionalidade - com a realidade objetiva dos problemas do país, leia-se industrialização e educação popular. Foi esta dupla perspectiva, segundo Fernando de Azevedo, que embalou seu projeto para a formação de um "[...] sistema de educação vivo e flexível, concebido como uma obra orgânica [...] e com uma lógica sistematização do pensamento moderno e uma consciência profunda das necessidades nacionais" (AZEVEDO, s.d.a, p. 53).

Ademais, como ressalta Vidal (1994), os ideais da construção de uma nacionalidade brasileira nos anos 1920-1930 se depararam com a questão da imigração, era preciso um projeto que abrangesse as massas imigrantes, e que não foi negligenciado por Fernando de Azevedo. A nossa composição étnica heterogênea, explica o educador, exigia que a organização da educação pública não se esquecesse das específicas necessidades de um povo em formação, que exigia "[...] a sua reforma em bases brasileiras, como força de coesão política e elemento consolidador de nossa composição [...]" (AZEVEDO, s.d.a, p. 
53). Nos tempos em presença, o autor analisou que o problema das correntes imigratórias se apresentava aos países nos seguintes termos: educar-se ou desaparecer.

A questão da incorporação, nos projetos de constituição da nacionalidade brasileira, das massas imigrantes não se apresentou apenas para Fernando de Azevedo, outros educadores, ligados ou não ao movimento escolanovista, posicionaram-se sobre o problema e formularam projetos postulando soluções para esta questão (CARVALHO, 1986). "O discurso sobre a construção da nacionalidade não era exclusivo dos educadores das décadas de 20 e 30, no Brasil” (VIDAL, 1994, p. 37), visto que a nacionalização de seus trabalhadores estrangeiros era fundamental do ponto de vista dos empresários.

Em seu projeto voltado à educação popular, caberia, a um só tempo, promover uma maior adaptação ao meio social - escola do trabalho -, "ensinar a viver em sociedade e a trabalhar em cooperação" - escola comunidade - e disseminar os ideais nacionalizantes e democráticos da civilização atual - escola única (AZEVEDO, s/d.a, p. 74). Para isto, o trabalho consistiria tanto no instrumento como no objetivo. Seria por meio da escola, do trabalho educativo (escola primária), que as atividades escolares se desenvolveriam, tendo por fundamento o trabalho: o fazer, o que se convencionou chamar de escola ativa ${ }^{5}$, assim como pela escola de trabalho produtivo (escola técnica profissional). A educação nova, por meio do trabalho educativo, estabeleceria o elo com o "[...] trabalho profissional e as atividades produtoras; ela tem, e deve despertar e desenvolver o sentido da vida econômica, o culto do trabalho, da máquina e da ciência [...]" (AZEVEDO, s.d.a, p.20).

Não se pode, no entanto, resumir seu projeto político a estes termos, isto é, que visasse apenas à preparação do trabalhador para a nova sociedade que se apresentava com o crescimento da indústria e a incorporação do imigrante, sob o preço de desconsiderar aspecto importante de seu pensamento. Em seu entender, o trabalho, a indústria e a ciência não têm fins em si mesmos, são importantes por serem instrumentos que possibilitam ao homem a criação e o gozo de ideais e de valores da cultura (AZEVEDO, s.d.a), isto é, pressupostos humanistas (modernos) dão o tom de seu pensamento.

No entender de Alves (2004, p. 36), embora seja após a Segunda Guerra Mundial, no livro Na Batalha do Humanismo: Aspirações, problemas e perspectivas, que Fernando de Azevedo formula, clara e refinadamente, sua concepção de humanismo científico (portanto moderno), já se encontravam, em seu pensamento, de maneira difusa, formulações nesse âmbito desde a elaboração do Inquérito, de 1926. A autora afirma ainda que o objetivo da elaboração teórica do autor nestes termos, quais sejam: lançando mão de uma filosofia de base humanista não clássica, era de fundamentar teoricamente uma política educacional defendida nesse Inquérito.

Esta estratégia (termo usado sem sentido pejorativo), para a autora, tem como propósito conferir um teor de universalidade ao discurso político-educacional do educador, bem como uma unidade intelectual que haveria de ter como ponto irradiador o próprio autor. Uma estratégia de publicidade que visa conquistar a opinião pública.

Para que a sociedade brasileira atingisse o patamar civilizatório - baseado na indústria, na ciência e na democracia -, alegava Azevedo, era preciso reorganizar o ensino, era urgente a socialização da escola, assim como fazer emergir um sentimento de entusiasmo e dedicação. O educador concebe que "[...] só os homens superiores são capazes de se guiarem por princípios e por ideias puras; o povo, em geral, se conduz por interesses e por sentimentos [...]". Postulava uma educação popular que fosse capaz de atingir a massa populacional. No seu entender, os instrumentos simbólicos seriam indispensáveis para a disseminação da cultura às classes populares e para a garantia do controle destas, em suas palavras: "[...] é preciso saber exaltar as forças do sentimento para 
que os homens nos sigam se quisermos dirigir os destinos de uma nação [...]" (AZEVEDO, 1948, p. 152).

A socialização da escola, para Fernando de Azevedo, nada mais era que a organização escolar de acordo com a nova finalidade social da educação que advogava. Não se pode confundir, no ideário azevediano, socialização da escola com democratização da escola. Referindo-se à sua reforma no Distrito Federal, 1928, o reformador explicou que sua intenção era adaptar a organização escolar às necessidades sociais de uma nova civilização. Foi exatamente este o significado do conceito. A escola, assim compreendida, deveria "[...] contribuir, pela sua própria organização interna, para formação do sentido social, com que se dilata, tornando-se mais intensa e profunda a obra de educação" (AZEVEDO, s.d.a, p. 82).

O conjunto de ideias e práticas enfeixadas no termo "socialização da escola" engloba: a) a adaptação da escola ao meio imediato; b) o exercício normal do trabalho em cooperação; c) a escola-comunidade; d) as cooperativas escolares. E, ainda, a articulação da escola com o meio social: a) a escola e a família; círculos de pais e professores; b) as enfermeiras escolares como visitadoras sanitárias; c) as excursões escolares; d) os conselhos escolares. Com todo esse aparato, a escola estaria pronta para ser um aparelho dinâmico de transformação (AZEVEDO, s.d.a, p. 81).

Para o autor, os interesses individuais se apresentavam quase sempre incoerentes, dispersivos e contraditórios. Numa sociedade capitalista industrial, ou, como define o autor, "[...] em sociedades cooperativas de produção e consumo", nas quais, segundo ele, as atividades sociais adquirem um caráter de cooperação, a educação não podia se guiar apenas pelas bases psicológicas do pensamento. O fundamental, em sua perspectiva, é que os sistemas de ensino fossem pautados nas tarefas ideais das sociedades humanas. A função coletiva que cada um assume no sistema social geral deveria guiar as condutas individuais. Os conceitos escolanovistas possibilitariam resolver, por meio da escola, os problemas das sociedades modernas (AZEVEDO, s.d.a).

A escola, pensada aos moldes da Escola Nova, fundamentou-se nos seguintes ideais: o trabalho em cooperação, a escola-comunidade ou a escola socializada. Para o autor, estes princípios contribuiriam para a formação do sentido social da escola e, mais ainda, auxiliaria na resolução dos problemas postos pela organização das sociedades modernas, por possibilitar e estimular a harmonia entre as classes (AZEVEDO, s.d.a).

A finalidade da educação, "apaziguadora da luta de classe", concatena-se com a concepção de Estado e sociedade de Fernando de Azevedo. Azevedo cita Kerschensteiner, a quem chama de notável educador alemão, para explicitar que se deve encarar o Estado "[...] como comunidade moral, isto é, como um produto histórico que tende cada vez mais à sua própria perfeição [...]" (AZEVEDO, s.d.a, p. 46). Refuta a "[...] doutrina que põe o Estado acima da Nação e faz dele o órgão da força pura e simples [...]"6. Para o educador, o Estado é a comunidade socialmente organizada (AZEVEDO, s.d.a, p. 50). Interpretando a ideia de Estado e sociedade de Fernando de Azevedo, Vidal (1994, p. 36) explica que "[...] sociedade, para ele, era uma face do Estado".

Nesta perspectiva, o Estado, sendo dirigido por elites modernas - oriundas de uma escola única e de uma escola socializada, formadas dentro dos ideais "socialistas" caminharia para sua perfeição, isto é, para um Estado socialista democrático.

Fernando de Azevedo se dizia socialista, em vários momentos de sua extensa obra, reclama essa posição política. Uma das passagens mais revisitadas por seus comentadores para ilustrar sua declarada filiação é a apresentada pelo autor em uma das suas obras 
autobiográficas: História da minha vida (1971, p. 210), da qual destacamos apenas a última frase da referida passagem.

Rigorosamente fiel ao princípio, que impõe a distinção fundamental entre ciência e ideologia, eu acabei tornando-me sob a inspiração de Karl Marx, um socialista, e, sob outras influências, as de Durkeim, sociólogo e um dos fundadores da Sociologia no Brasil.

A respeito de certo mal-estar que a declaração suscitou, Candido (1994, p. 16) defende que a ação do educador enquanto reformador era guiada pelo "espírito de reforma", que o levava a colaborar com governos que iam ao encontro de proclamados ideais políticos. Durmeval Trigueiro Mendes (1987, p. 19) é menos indulgente, “[...] a despeito de ser liberal [refere-se ao educador] ele pretende ser socialista, desprotegido, porém, de categorias adequadas". Não é nossa intenção, neste estudo, enveredarmos por esta discussão, apenas assinalarmos que as propostas para a sociedade e a educação brasileiras, saídas do punho de Fernando de Azevedo, propõem, ou se propõem a uma silhueta socialista, como indicou Candido, um socialismo de cunho democrático.

Foi com a ambição da necessidade de renovação das elites que, em seu projeto político, a formação das elites ganhou evidência. Foi também sob esta lógica que seu projeto de educação do povo foi elaborado. Reside aí, segundo o reformador, um dos pontos mais radicais de seu pensamento. Concebia inviável uma modernização da classe dirigente que não passasse pela democratização da escola. Ao atingir a educação das massas populares, entendia ele, abrir-se-iam "caminho e oportunidade à solução do problema da formação das classes médias e dirigentes [...]" (AZEVEDO, s.d.a, p. 143).

Para ele, a formação das elites e a educação popular formavam um único problema, cuja solução pulverizaria inúmeros outros problemas. Um dos problemas, cuja resolução passava por esta questão, era que "[...] as elites, formadas em centros universitários, sem contato com as camadas profundas da sociedade, acabariam por constituir uma aristocracia, inacessível e fechada [...]". Por sua vez, "a educação das massas populares, sem a formação de elites capazes de orientá-las e dirigi-las, importaria na mobilização de forças, para a pior das demagogias [...]” (AZEVEDO, s.d.a, p. 106).

Em sua orientação, a educação popular era um momento indispensável da formação das elites. Aí se enuncia uma das ideias-força de seu projeto político-educacional: a "circulação das elites". Para o autor, democratizando o acesso à educação, democratizar-seia a sociedade, posto que as classes dirigentes, periodicamente, seriam substituídas. Tal obra caberia à universidade realizar, selecionando e preparando os mais aptos. Assim, estabelecerse-ia um sistema permanente de renovação constante das elites governantes "[...] um sistema de circulação, que mantém a vitalidade fecunda das verdadeiras democracias [...]" (AZEVEDO, s.d.a, p.106, grifo do autor).

A teoria da circulação das elites foi desenvolvida originalmente por Vilfredo Pareto, um economista e sociólogo italiano, que viveu entre 1848 e 1923. Sua teoria, segundo Queiroz (1994), provinha da constatação de Pareto de que, no poder, sempre havia um grupo que exercia o poder de mando. Pareto acreditava que, em todos os grupos que compõem as diversas sociedades, haveria sempre um pequeno número de indivíduos exercendo o poder sobre os demais. Paulatinamente, os indivíduos que estavam fora dos círculos dominantes se infiltrariam, articulando-se aos outros que lá se encontravam. Nesse encontro, haveria uma adaptação, uma rearticulação ou ainda uma substituição de uma elite por outra. Essa ascensão de um grupo seria acompanhada pela decadência do outro grupo. Queiroz (1994) esclarece que não foi apenas Pareto que encampou esta ideia, vários outros seguiram a mesma trilha, cita o sociólogo alemão Robert Michels (1875-1940), Josep 
Schumpeter (1883-1950), o sociólogo francês Raymond Aron (1905-1983) e, ainda, o sociólogo americano Wright Mills (1916-1962).

É preciso apreender a posição que a educação assumiu na composição do pensamento de Fernando de Azevedo e como ele analisou a evolução histórica do país para iluminar sua leitura e aplicação da teoria da "circulação das elites". Evitamos reduzir a complexidade de sua construção teórica e cair em armadilhas que priorizam simplificações e atalhos para caracterizar o pensamento e a ação do intelectual.

Conceitos do tipo "elitista" e "contraditório" pouco nos ajudam a entender a dialética de sua vida e obra se não forem vistos apenas como indicativos de aproximação e distanciamento de determinadas concepções de vida e sociedade e não como condenações sumárias que invalidam a possibilidade de qualquer contribuição intelectual ou prática. É preciso entender como o autor construiu sua teoria, as articulações que fez. Não é o caso de se afirmar, como pondera Queiroz (1994, p. 62), que Fernando de Azevedo fosse sempre coerente em seu pensamento e agir, "[...] que em suas ideias e ações não interviessem oposições, incoerências, contradições [...]". Trata-se de entendê-lo como um sujeito histórico, portanto, contraditório, que se posicionou perante problemas concretos de sua época com o instrumental que sua existência permitiu.

Pautado nas teorias desenvolvidas por Dürkheim ${ }^{8}$, Fernando de Azevedo, imerso num contexto de crise da sociedade agrário-exportadora (década de 1920) - no qual vários projetos se cruzavam na tentativa de renovações sociais, culturais e políticas -, viu, nas elaborações do sociólogo francês, diretrizes válidas para a interpretação da sociedade brasileira, bem como para a elaboração de soluções (QUEIROZ, 1994, p. 54). Todo seu empenho foi para defender transformações no âmbito educacional, porque, se a educação livresca, literária, verbalista, intelectualista, aristocrática e escolástica - usando alguns de seus termos - não foi útil nos períodos anteriores (Colônia e Império), pior ainda na República, com as forças industrialistas já em desenvolvimento.

$\mathrm{Na}$ transição para a modernidade capitalista no Brasil, o ideário liberal assumiu a direção ideológica e, nesse contexto, os liberais entendiam que a força propulsora das transformações sociais, políticas e econômicas que desejavam estaria na cultura, mais especificamente, numa concepção de cultura pragmática e moderna. Para os liberais envolvidos com o campo educacional - os pioneiros da educação renovada -, a cultura passara a ser concebida como a via para a promoção de uma reforma na mentalidade da população nacional, reforma esta que levaria a uma "revolução da ordem" (MONARCHA, 1990). A ordem que os defensores da modernidade queriam romper não era a ordem capitalista, e sim a situação de atraso do desenvolvimento capitalista da sociedade agroexportadora.

No pensamento de Fernando de Azevedo essa ideia também se fez presente. Entendia que, se uma sociedade quer "[...] preservar a sua existência e assegurar o seu progresso, longe de contentar-se com atender às exigências de sua vida material, tende a satisfazer às suas necessidades espirituais [...]". Para garantir a satisfação dessas necessidades espirituais, seria preciso "[...] uma elite incessantemente renovada, de indivíduos, sábios, pensadores e artistas que constituem uma certa formação social, acima das classes e fora delas (AZEVEDO, 1996, p. 38).

Sob o prisma interpretativo azevediano, alijadas de uma cultura prática e científica, as elites brasileiras dos diferentes períodos da história do país não permitiram transformações essenciais na estrutura da sociedade e nem uma adequada democratização da educação (expansão educacional às classes populares) para que possibilitasse uma renovação constante das classes dirigentes e, com isto, um maior progresso econômico, social e cultural para a nação. Firmando-se nesta acepção, Fernando de Azevedo 
proclamava a necessidade de formação adequada para as elites e, mais, uma mudança de mentalidade, sobretudo para as classes dirigentes.

Ao analisar a sociedade de sua época, particularmente nos anos 1920-1930, indicou sua movimentação no interior do quadro das elites. Percebeu ainda que o aumento de camadas sociais, proporcionado pela industrialização e urbanização, não significou a mudança do núcleo constituído por alguns grupos familiares, que continuavam sempre o mesmo no exercício do mando político. Entendeu que as novas forças oriundas de outras classes sociais, quando ascendiam à classe dirigente, portavam-se da mesma forma que as antigas elites. Concluiu que, "[...] desse modo, a estrutura sócio-política, em lugar de abalada por estes dois processos [industrialização e urbanização] bastante diversos dos anteriores, foi fortalecida pelas mudanças por eles determinadas" (QUEIROZ, 1994, p. 63).

Qual a solução encontrada pelo sociólogo-educador? A preparação das elites, a educação popular e a socialização da escola. Isto favoreceria uma maior circulação das elites e uma mudança de mentalidade, já que, formadas a princípio numa escola única, conviveriam de perto com crianças de outras camadas sociais, inclusive e especialmente com a classe popular. Assim, entenderiam a necessidade da educação popular e não seriam parasitárias, mas, modernas. Da mesma forma, a classe popular, por ter convivido de perto com os filhos das elites, desenvolveria uma complacência, uma simpatia por estas. Tudo somado, o projeto pensado por ele resolveria inúmeros problemas, e o principal: a harmonia entre as classes.

Fernando de Azevedo vislumbrou a tendência negativa que a distância entre as classes injetava na sociedade, explica Candido (1994, p. 14-15). Para barrar ou mesmo limitar o fosso entre as classes sociais, a solução, para o educador, parecia estar numa filosofia educacional pertinente, numa legislação unificada e na articulação vertical do ensino.

Explica Queiroz (1994, p. 65) que a assimilação do conceito de "circulação das elites" por Fernando de Azevedo estava coerente com sua intenção enquanto sociólogo, que buscou, no instrumental disponível em sua época, analisar a sociedade a qual pertencia, tentando fugir de uma linguagem puramente descritiva. Na concepção da autora, não "[...] estava sendo incoerente com sua posição política de socialista, embora o termo tivesse sido definido por um opositor do marxismo e para fazer frente a este" (QUEIROZ, 1994, p. 65). Porque sua condição de sociólogo, seu entendimento da sociologia e sua concepção desta ciência lhe permitiam reconhecer "[...] a utilidade de uma ferramenta adequada ao que pretendia esclarecer, não importando as idéias políticas de quem as havia inventado [...]" (QUEIROZ, 1994, p. 65). Por outra, sua crença na neutralidade da ciência o redimia.

Esta postura do intelectual parece expediente frequente não apenas em seu pensamento como também nas posições políticas e no modo como encarou os governos dos quais participou. Antônio Candido (1994) refere-se ao autor como dono de uma "[...] mentalidade política sui generis" centrada na educação e na cultura, sem ter, no entanto, "[...] qualquer vinculação ou mesmo interesse partidário" (p. 15). Isto, aliado à sua crença no poder democratizador da educação, levou-o a pactuar (no sentido de colaborar) com vários governos, fossem conservadores, como Washington Luís, Antônio Prado Junior, ou autoritários, impostos pelo governo federal, como Waldomiro de Lima, e até liberais, como Armando de Salles Oliveira. Foi, ainda, "dentro desta disposição fundamental", conclui o autor, que Fernando de Azevedo "[...] analisou com imparcialidade os atos dos diferentes governos Vargas [...]" (CANDIDO, 1994, p. 15).

Despindo de todo sentido negativo, Candido (1994) utiliza o termo "oportunista desinteressado" para qualificar Fernando de Azevedo e suas ações políticas e reformas 
educacionais. Dimas (1994) evoca as angústias do sociólogo-reformador que vivia entre as necessidades de dois mundos: a do intelectual que sempre foi e a de planejador de políticas educacionais. Um homem que, das vicissitudes da vida pública e do conforto da reflexão acadêmica, nunca fugiu. "Um homem duplo, mistura de sonhador e de administrador [...]" (DIMAS, 1994, p. 32-33).

Com este perfil e imerso num cenário de mudanças dos paradigmas intelectuais brasileiros e num contexto de grandes transformações sócio-históricas, pôs sobre seus ombros a missão de reformar a sociedade, tendo por via principal a estruturação orgânica do ensino público. E lançou mão, por ser um homem culto, de diferentes e divergentes elaborações filosóficas e construtos científicos para criar soluções plausíveis para a realidade nacional. Construiu um arcabouço teórico para justificar sua ação administrativa e política.

\section{Intelectuais e Estado nos anos 1920-1930}

No período em foco, havia, no Brasil, um desenvolvimento econômico e político de setores considerados mais modernos, como a indústria e uma crescente urbanização da sociedade. Concomitante a estes fatos, passou-se a defender a necessidade da formação de um novo tipo de homem para esse novo tipo de sociedade que apontava como horizonte. Nesse período, diversos projetos políticos se complementavam na tentativa de construir o cidadão trabalhador para uma sociedade democrática e industrial.

O processo histórico é um todo indissociável, as questões econômicas, políticas, sociais, culturais e educacionais estão imbricadas numa relação dialética complexa. A década de 1920 foi marcada pelas contradições estruturais, inerentes a períodos de transição da base econômica e suas repercussões no campo político, assim como por importantes acontecimentos sociais e culturais. Desde o romper dos anos 1920, foi iniciado um movimento amplo no qual vários setores da sociedade entraram num processo denominado de transformação modernizadora. A criação do Partido Comunista Brasileiro (PCB) em 1922; o crescimento das camadas médias urbanas ${ }^{9}$; os movimentos grevistas operários $^{10}$; a insatisfação dos trabalhadores rurais e urbanos com o modelo sociopolíticoeconômico, expressa em revoltas ${ }^{11}$ e $\operatorname{protestos}^{12}$; rebelião militar (tenentismo); e o movimento artístico-intelectual autodenominado "movimento modernista" demarcaram, no campo social e cultural, as agitações do período.

Foi nesse momento que a educação pública se configurou como um movimento social. Os intelectuais envolvidos com o campo educacional não foram os únicos a se articular pela causa social. Outros grupos, como os modernistas e os médicos sanitaristas, também se organizaram. Similarmente, estava nascendo uma intelectualidade desejosa de transformar a sociedade e a cultura do país em moldes mais modernos.

Nosso desenvolvimento histórico, explica Carvalho (1997), sedimentou-se no avanço do Estado, que, aos poucos, foi penetrando na sociedade. O caminho percorrido, centrado no papel do Estado, resultou numa dominação e numa configuração política diversa da ocorrida em outros países. Os conceitos-chave para apreender a natureza dessa dominação e a formação política brasileira são: o patrimonialismo, o clientelismo, o coronelismo, o populismo e corporativismo.

Esta característica do desenvolvimento histórico brasileiro gerou uma forma de organização política que possibilitou um aprofundamento das práticas políticas coronelistas. É possível identificar o lastro que ligou o ideário de um grupo de intelectuais a este processo. O federalismo, forma que a organização política brasileira assumiu com a 
Proclamação da República, evidenciou as disputas individuais e os interesses de grupos regionais que assumiram a dianteira da condução política.

No contexto de crise da economia agroexportadora, essa configuração foi alvo de profundas críticas, sobretudo por uma parte dos intelectuais, os quais pensavam o Estado como o único capaz de realizar a democratização dos bens sociais e culturais. Entretanto este Estado deveria se desvencilhar das vicissitudes da política oligárquica.

Devido à particularidade do processo de desenvolvimento das forças sociais e produtivas do Brasil, não foi apenas a iniciativa privada, mas o Estado também apareceu como peça fundamental no movimento de acumulação de capital e de desenvolvimento das forças produtivas nacionais. No período, a modernidade que a intelectualidade defendia guardava ligações com o desenvolvimento industrial. Entendiam os intelectuais que, para o país entrar no conjunto das grandes nações modernas, era preciso que se industrializasse.

$\mathrm{O}$ pensamento dominante esteve articulado à condição do processo de desenvolvimento histórico, isto é, à entrada do Estado nas esferas da economia como agente modernizador. Daí que a intelectualidade do período postulava que o Estado aderisse aos ditos serviços sociais, entendidos como processo indispensável à modernização não apenas econômica, mas política, social e cultural.

Segundo Bomeny (2001), desde os anos 1920, os intelectuais propugnavam formulações de políticas públicas para as áreas da cultura, educação, ciência, patrimônio, previdência. "Educação, ciência e cultura de uma nação à espera de um Estado que as resgatasse em benefício de todos, que as garantisse como patrimônio social" (BOMENY, 2001, p. 18-19). Na verdade, ciência, educação e cultura dividiram a dianteira dos principais problemas do país na opinião dos doutos que se propuseram a analisar a nação a partir do arcabouço do pensamento democrático-liberal-progressista no período 19201930.

Embasando-nos nas formulações de Bomeny (2001), podemos chegar à afirmação de que, desde os anos 1920, havia na intelectualidade brasileira uma pré-disposição, digamos assim, para atuar diretamente nos quadros do aparelho de Estado. A montagem de um Estado, cuja característica era a implantação de políticas de proteção social para as mais diversas áreas, explicaria, em parte, a participação dos intelectuais nos governos a partir de então.

A ampliação da intervenção da sociedade política na regulação da sociedade civil, tanto no âmbito dos estados e do Distrito Federal quanto no da União, é identificada nos anos 1920-1930. O entendimento desse processo de transformação da natureza do poder contribuiu para o alargamento de nosso entendimento entre relação intelectual e Estado. Se, por um lado, o pensamento dominante no campo intelectual entendeu ser necessária a constituição de um Estado com maior sentido público, do outro, da classe dirigente, houve a defesa da necessidade de constituição de um Estado com capacidade de intervenção maior em vários campos da vida social e da economia.

O surgimento político de setores de trabalhadores e a nova característica que a classe trabalhadora assumiu nesse período de transição também foi um dos motores das formações ideológicas e dos ideais de democracia e progresso, verificados no pensamento intelectual brasileiro da época. Bomeny (2001) chama a atenção para o termo progresso, que foi entendido pela via da ordem, significando um tolhimento de ideais democráticos e uma supervalorização de conceitos como organização, tecnificação e racionalização.

Houve ainda outros fatores, Miceli (2001, p.78), ao tratar das relações entre os intelectuais e a classe dirigente no Brasil entre 1920-1945, aponta que as transformações, econômica, social, política e cultural dessas décadas assinalaram uma mudança na condução política. Nesse período, a coalizão de forças à frente do Estado procurou marcar 
uma pretensa distância em relação aos antigos grupos dirigentes e, ao mesmo tempo, buscou novas formas de garantir a dominação e a conservação do status quo. Passou a intensificar sua ação de dominação, atuando mais de perto nos diversos níveis do sistema de ensino e no campo da produção e da difusão cultural.

Foi no processo de ampliação e complexificação das relações de dominação no campo político que, segundo Miceli (2001), os intelectuais, em particular os educadores profissionais, foram recrutados pelo Estado, visto que necessitava de quadros profissionais para diferenciar sua ação política e dar legitimidade ao seu projeto de modernização da sociedade e às suas políticas públicas. Foi uma tentativa de alguns segmentos da oligarquia no tumultuado contexto de crise da sociedade agrário-exportadora para permanecer no comando do aparelho de Estado.

$\mathrm{Na}$ interessante análise de Alves (2004), os anos 1920 e 1930 representaram o início de outra forma de fazer política. Forma esta que "[...] implicava em conferir à ação empreendida pelo Estado uma autoridade científica e especializada, decorrente da atividade dos intelectuais" (p. 56). Acrescenta o autor que estes seriam "[...] uma espécie de corpo político especializado a orientar a ação pública, ou a partir da sociedade civil ou do estado" (p. 56).

Foi nesse contexto que os intelectuais da educação encontraram um lugar ao sol dentro do Estado. A ação no meio educativo lhes possibilitou projeção e visibilidade no cenário político nacional como especialistas no assunto (MICELI, 2001). No momento anos 1920-1930 - em que o poder constituído - leiam-se elites paulistas e mineiras tentava se desvencilhar das críticas e superar a crise econômica e de hegemonia e no momento de reformular as alianças políticas e construir uma nova forma de organização do Estado.

Em períodos de crise de hegemonia, a classe dominante tende a reavivar antigos ideais, os quais estiveram na base da construção da hegemonia ora contestada. Tal procedimento explica em parte o fôlego novo que marcou a ascensão do pensamento democrático - o mesmo que esteve presente nos discursos republicanos pronunciados na aurora da Proclamação da República, nos anos 1920-1930. A bandeira: "republicanizar a república" estampa, de forma emblemática, este postulado. Vários intelectuais e políticos repousaram seus projetos societários no pensamento liberal republicano. A ideia de escolarização do povo esteve articulada ao de aperfeiçoamento do sistema representativo e da democracia. E a participação de intelectuais nos aparelhos de Estado esteve articulada à crise de hegemonia da classe dirigente paulista e mineira e ao surgimento de novas frações de classe que requeriam o poder de Estado para si.

Seria um erro, no entanto, acreditar que o pensamento que cimentou o ideário educacional-democrático, defendido pelos chamados escolanovistas nos anos 1920 e 1930, fosse tão-somente uma retomada de velhas bandeiras republicanas. Mesmo que isto fosse verdade, num contexto diferente, velhos ideais e objetivos adquiriram novos contornos e significados.

A nossa constituição histórica justificava os posicionamentos dos intelectuais nessas décadas, que desconfiaram da capacidade e das intenções dos setores privados para empreender ações no campo social e depositaram suas esperanças na ação da sociedade política, porém requerendo outra forma de organização, o Estado Nacional Centralizado (BOMENY, 2001). Podemos entender ainda a defesa da necessidade de constituição de políticas públicas de cunho nacional, dentre estas a construção de um sistema público de ensino articulado nacionalmente. A intelectualidade queria romper com a ordem oligárquica tradicional, marcada pelo personalismo político e pela falta de sentido público do Estado sob o comando das oligarquias regionais. 
A construção de um Estado promotor de políticas sociais foi uma via para o progresso dentro da ordem, este foi o pensamento dominante nos anos 1920-1930. A crítica ao governo das oligarquias regionais se transferiu para o federalismo, a forma política que as possibilitava. A crítica de parte dos intelectuais era que o Estado oligárquico jamais seria capaz de promover o progresso social da nação, cunhado que estava dos interesses individuais e particulares dos coronéis.

\section{Considerações Finais}

Fernando de Azevedo viveu em um contexto de rearticulação das potências internacionais, de mudanças no modo de produção capitalista e de surgimento político de novas classes sociais no Brasil e expressa em seu pensamento e atuação as contradições de seu tempo. A necessidade de a sociedade brasileira reorganizar a educação é atribuída, segundo esse educador, entre outras coisas, à exigência dos tempos modernos de se emparelhar educação e sociedade.

Entendemos que as ideias de Fernando de Azevedo jamais seriam suficientemente compreendidas se não fossem vistas como produto da reflexão de um sujeito histórico, isto é, de um ser humano dotado de necessidades, preocupações e anseios, cujas características dependiam das bases materiais em que se estruturava a sociedade a que pertencia.

Neste sentido, as ideias e ações educacionais de Azevedo devem ser entendidas de forma articulada ao do grupo que se formou em torno da Escola Nova - admitindo-se aproximações e distinções entre eles -, que propalava a necessidade da reforma da educação como integrante da reforma da sociedade com vistas à condução da nação brasileira rumo à civilização e ao progresso. Similarmente, deve o pensamento escolanovista ser apreendido em estreita relação com a sociedade e as condições históricas resultantes de um profundo processo de transformações social, política e econômica. Esse processo, na verdade, foi o início e a consolidação da organização de um sistema de princípios políticos, econômicos e sociais que deram sustentação à moderna sociedade industrial.

\section{Referências}

ALVES, Catharina Edna Rodrigues. Fernando de Azevedo: na batalha do humanismo. 2004. 125 f. Dissertação (Mestrado em Educação) - Universidade Estadual Paulista, Faculdade de Filosofia e Ciências, Marília, SP, 2004.

AZEVEDO, Fernando de. A educação e seus problemas. 4. ed. São Paulo: Melhoramentos, 1948.

AZEVEDO, Fernando de. História de minha vida. Rio de Janeiro: José Olympio, 1971.

AZEVEDO, Fernando de. A cultura brasileira. 6. ed. Brasília, DF: Ed. UnB; Rio de Janeiro: Ed. UFRJ, 1996.

AZEVEDO, Fernando de. Novos caminhos e novos fins: a nova política de educação no Brasil. 3. ed. São Paulo: Melhoramentos, s.d.a.

AZEVEDO, Fernando de. A reconstrução educacional no Brasil. Manifesto dos Pioneiros da Educação Nova (1932). In: AZEVEDO, Fernando de. A educação entre dois mundos. Problemas, perspectivas e orientações. São Paulo: Melhoramentos, s.d.b. p. 59-81. 
BOMENY, Helena. Infidelidades eletivas: intelectuais e política. In: . (Org.).

Constelação Capanema: intelectuais e política. Rio de Janeiro: Fundação Getúlio Vargas / Bragança Paulista: Ed. Universidade de São Francisco, 2001. p. 11-35.

CANDIDO, Antônio. Um reformador. Revista do Instituto de Estudos Brasileiros, São Paulo, n. 37, p. 11-17, 1994.

CARVALHO, José Murilo de. Mandonismo, coronelismo, clientelismo: uma discussão conceitual. Dados - Revista de Ciências Sociais, Rio de Janeiro, v. 40, n. 2, p. 229-250, 1997.

CARVAlHO, Marta Maria Chagas de. A escola e a República. São Paulo: Brasiliense, 1986.

CUNHA, Marcus Vinicius da. Dewey, escola nova e construtivismo: continuidade, descontinuidade e recontextualização. In: ALMEIDA, Jane Soares de (Org.). Estudos sobre a profissão docente. São Paulo: Cultura Acadêmica, 2001. p. 15-44.

DIMAS, Antônio. Os primeiros leitores de A cultura brasileira. Revista do Instituto de Estudos Brasileiros, São Paulo, n. 37, p. 19-33, 1994.

FAUSTO, Boris. A revolução de 1930: história e historiografia. São Paulo: Brasiliense, 1978.

GRAMSCI, Antonio. Maquiavel: a política e o estado moderno. 8. ed. Rio de Janeiro: Civilização Brasileira, 1991.

GRAMSCI, Antônio. Notas sobre Maquiavel. In: SADER, Emir (Org.) Gramsci: poder, política e partido. São Paulo: Expressão Popular, 2005. p. 11-105.

MENDES, Durmeval Trigueiro. Prefácio. In: PENNA, Maria Luiza. Fernando de Azevedo: educação e transformação. São Paulo: Perspectiva, 1987. p. 13-19.

MICELI, Sérgio. Intelectuais à brasileira. São Paulo: Companhia das Letras, 2001.

MONARCHA, Carlos. A reinvenção da cidade e da multidão. Dimensões da modernidade brasileira: a escola nova. São Paulo: Cortez: Campinas-SP: Autores Associados, 1990.

MOURA, Antônio Plínio Pires de. Brasil industrial: do capitalismo retardatário à inserção subordinada no mundo neocolonial. Bahia Análise e Dados, Salvador, v. 11, n. 3, p. 8289, dez. 2001.

PERISSINOTO, Renato M. Classes dominantes e hegemonia na República Velha. Campinas, SP: Ed. Unicamp, 1994.

PINTO, Diana Couto et al. Trajetórias de liberais e radicais pela educação pública: Anísio Teixeira, Darcy Ribeiro, Fernando de Azevedo, Florestan Fernandes. São Paulo: Loyola, 2000.

POULANTZAS, Nicos. Poder político e classes sociais do estado capitalista. Porto: Portucalense, 1971.

QUEIROZ, Maria Isaura P. de. Fernando de Azevedo: o sociólogo. Revista do Instituto de Estudos Brasileiros, São Paulo, n. 37, p. 53-69, 1994. 
RIBEIRO, Maria Luísa S. História da educação brasileira. A organização escolar. São Paulo: Moraes, 1986.

SAES, Décio. Classe média e política na Primeira República brasileira (1889-1930). Petrópolis, RJ: Vozes, 1978.

SAES, Décio. Coronelismo e Estado burguês: elementos para uma reinterpretação. Nova Escrita - Ensaio, São Paulo, v. 4, n. 9, p. 107-127, s.d.

SAVIANI, Dermeval. História das ideias pedagógicas no Brasil. Campinas, SP: Editores Associados, 2007.

SEVCENKO, Nicolau. Transformações da linguagem e advento da cultura modernista no Brasil. Estudos Históricos, Rio de Janeiro, v. 6, n. 11, p. 78-88, 1993.

VIDAL, Diana. Nacionalismo e tradição na prática discursiva de Fernando de Azevedo. Revista do Instituto de Estudos Brasileiros, São Paulo, n. 37, p. 35-51, 1994.

\section{Notas}

${ }^{1}$ Mestre em Educação e graduada em História pela Universidade Estadual de Maringá.

${ }^{2}$ Doutora em História pela PUC-SP, docente do Departamento de Fundamentos da Educação e do Programa de Pós-Graduação em Educação na Universidade Estadual de Maringá.

${ }^{3}$ Segundo Queiroz (1994, p. 54): “[...] a primeira manifestação de seu entusiasmo pela nova maneira de encarar a sociedade e a educação se inscreveu num inquérito que promoveu em 1925, através do jornal $O$ Estado de S. Paulo, sobre a introdução da Sociologia, e naturalmente da Sociologia Educacional, nas Escolas Normais Primárias, renovando a formação dos mestres".

4 Ao diferenciar a economia açucareira da economia cafeeira, Saviani (2007) assinala que a segunda guarda uma especificidade, lança mão do Estado sem mediadores, em suas palavras "[...] a economia cafeeira contou, desde o início, com uma vanguarda constituída por homens com experiência comercial, entrelaçando-se, assim, os interesses da produção e os do comércio. [...] Tendo consciência clara de seus interesses, esses dirigentes compreenderam a importância do governo na atividade econômica, o que os levou a colocar a política a serviço do grupo econômico por eles representado" (p. 160).

5 Azevedo (s.d.a, p. 76) define "escola ativa" como: "[...] a escola em que a atividade é aproveitada como instrumento de ensino e educação [...]". É preciso destacar, porém, que, em sua concepção de "escola do trabalho", esta perspectiva é ampliada, alinhando-se mais à perspectiva de Kerschenstein, "a escola do trabalho é a escola em que a atividade é aproveitada como um instrumento ou meio de educação. Nada se aprende, senão fazendo: trabalhando" (p. 73).

6 Discurso pronunciado por Fernando de Azevedo em 19 de setembro de 1937, no Rio de Janeiro, na cerimônia de sua posse para a presidência da Associação Brasileira de Educação (1948, p. 26).

7 "A escola socializada, reconstituída sob a base da atividade e da produção, em que se considera o trabalho como a melhor maneira de estudar a realidade em geral (aquisição ativa de cultura) e a melhor maneira de estudar o trabalho em si mesmo, como fundamento da sociedade humana, se organizou para remontar a corrente e restabelecer, entre os homens, o espírito de disciplina, solidariedade e cooperação por uma profunda obra social que ultrapassa largamente o quadro estreito dos interesses de classe" (AZEVEDO, s.d.b, p. 64).

8 As teorias desenvolvidas por Dürkheim sobre a educação postulavam, em linhas gerais, que "[...] cada sociedade engendrava o 'seu' sistema de educação, cujas funções se voltavam para a socialização dos indivíduos a ela pertencentes e para a perpetuação dos valores que lhe eram peculiares [...]" e que "[...] uma crise no sistema pedagógico de um país indicaria uma crise no sistema social [...]” (QUEIROZ, 1994, p. 54).

9 Entende-se "camadas médias" como sinônimo de "classe média": funcionários públicos; pequenos comerciantes; funcionários das casas exportadoras; profissionais liberais, como sinônimo de "[...] população civil urbana, que trabalha por conta própria ou que recebe salários por trabalho não-manual [...]" (FAUSTO, 1978, p. 54). 
10 "Nos anos de 1917 e 1918, os movimentos grevistas recrudesceram e aconteceu a primeira greve geral em São Paulo, que durou 30 dias e chegou a levar o governador a abandonar a cidade" (RIBEIRO, 1986, p. 92).

${ }^{11}$ Segundo Saes (1978, p. 35), “[...] as revoltas rurais detonadas ao longo da Primeira República não foram inexpressivas; na região cafeeira, sobretudo, sua violência impeliu os poderes oligárquicos locais à prática da repressão mais sangrenta [...]". Essas constatações desmentem as análises que frisam a passividade e a submissão do trabalhador rural do período.

12 "Nas cidades do Centro-Sul, o isolamento social e político da classe operária, em formação desde o início do século XX, impulsionou-a para as formas de ação anarquista e anarco-sindicalista. À atitude oligárquica de tratamento dos problemas operários como um caso criminal, ou seja, de repressão, a classe operária reagia através da adoção das formas mais radicais de combate ao poder oligárquico: a orientação anarquista do primeiro Partido Comunista do Brasil e a greve geral de 1917 em São Paulo [...]" (SAES, 1978, p. 35).

Recebido em setembro-13

Aprovado em novembro-13 